\title{
Information Behavior and HIV Testing Intentions Among Young Men at Risk for HIV/AIDS
}

\author{
Chrysta C. Meadowbrooke and Tiffany C. Veinot \\ School of Information, University of Michigan, 4429 North Quad, 105 South State Street, Ann Arbor, MI \\ 48109-1285. E-mail: \{cmeadow, tveinot\}@umich.edu \\ Jimena Loveluck \\ HIVIAIDS Resource Center, 3075 Clark Road, Suite 203, Ypsilanti, MI 48197. \\ E-mail: loveluck@hivaidsresource.org \\ Andrew Hickok and José A. Bauermeister \\ School of Public Health, University of Michigan, 1415 Washington Heights, Ann Arbor, MI 48109-2029. \\ E-mail: \{ahickock, jbauerme\}@umich.edu
}

\begin{abstract}
Health research shows that knowing about health risks may not translate into behavior change. However, such research typically operationalizes health information acquisition with knowledge tests. Information scientists who investigate socially embedded information behaviors could help improve understanding of potential associations between information behavior-as opposed to knowledge - and health behavior formation, thus providing new opportunities to investigate the effects of health information. We examine the associations between information behavior and HIV testing intentions among young men who have sex with men (YMSM), a group with high rates of unrecognized HIV infection. We used the theory of planned behavior (TPB) to predict intentions to seek HIV testing in an online sample of 163 YMSM. Multiple regression and recursive path analysis were used to test two models: (a) the basic TPB model and (b) an adapted model that added the direct effects of three information behaviors (information exposure, use of information to make HIV-testing decisions, prior experience obtaining an HIV test) plus self-rated HIV knowledge. As hypothesized, our adapted model improved predictions, explaining more than twice as much variance as the original TPB model. The results suggest that information behaviors may be more important predictors of health behavior intentions than previously acknowledged.
\end{abstract}

\section{Introduction}

Encouraging people to get tested for HIV and reducing barriers to testing are major components of the U.S. public

Received February 11, 2013; revised April 16, 2013; accepted April 17, 2013

(C) 2014 ASIS\&T • Published online 15 January 2014 in Wiley Online Library (wileyonlinelibrary.com). DOI: 10.1002/asi.23001 health strategy to decrease HIV transmission (Centers for Disease Control and Prevention, 2003; Noar, Palmgreen, Chabot, Dobransky, \& Zimmerman, 2009). Combined with a commitment to risk reduction behaviors, HIV testing has the potential to help prevent new cases of infection. The Centers for Disease Control and Prevention guidelines recommend that sexually active men who have sex with men (MSM) should get tested for HIV at least once a year and every 3 to 6 months if they engage in risk behaviors (Workowski \& Berman, 2010). Since the late 2000s, the availability of rapid HIV testing has increased the number of people at risk of infection who receive their results, leading to the opportunity to obtain early treatment if warranted (Bowles et al., 2008). The U.S. Food and Drug Administration recently approved over-the-counter kits for in-home rapid HIV testing, which may further increase access to testing (Carballo-Diéguez, Frasca, Balan, Ibitoye, \& Dolezal, 2012; U.S. Food and Drug Administration, 2012; Willyard, 2012). Years of HIV testing programs and public health campaigns have succeeded in decreasing the overall HIV transmission rate from about $43 \%$ in 1983 to roughly 4\% each year since 1990 (Holtgrave \& Curran, 2006). However, the continued spread of the virus from persons living with HIV, including those who do not know their serostatus, remains a serious concern since many people have never been tested or do not test regularly despite engaging in risky behaviors (El-Sadr, Mayer, \& Hodder, 2010).

From 2001 to 2004, HIV diagnosis rates increased more per year for young men who have sex with men (YMSM) younger than age 24 than for older MSM in the United States (Hall, Byers, Ling, \& Espinoza, 2007). From 2006 to 2009, although the overall incidence rate of new HIV 
diagnoses in the United States remained relatively stable, the incidence among YMSM of any race increased by $34 \%$ and by $48 \%$ among African American YMSM (Prejean et al., 2011). YMSM are not only at a disproportionate risk for HIV infection but also might be less likely to know whether they have become infected. For example, MacKellar et al. (2005) found that $77 \%$ of 575 YMSM from six major U.S. cities who received positive results for HIV when the researchers tested them had not known their status. Of those unaware of their infection, $55 \%$ had been tested more than a year earlier or had never been tested. Understanding why YMSM decide to seek or avoid HIV testing may help improve efforts to motivate them to obtain regular HIV tests (Kellerman et al., 2002), a goal that may eventually reduce HIV transmission rates.

Educational campaigns that convey HIV information through service providers and mass media have been credited with helping to prevent HIV transmission (Albarracín et al., 2005; Holtgrave \& Curran, 2006). Understanding information about HIV transmission is clearly necessary for people to take appropriate steps to prevent infection. Yet some researchers have reported a knowledge-behavior gap, finding that knowledge on its own is not sufficient for stimulating HIV/AIDS-related behavior change (Baldwin, Whiteley, \& Baldwin, 1990; Fisher \& Fisher, 1992; Rimal, 2000; Sheeran, Abraham, \& Orbell, 1999; Sligo \& Jameson, 2000). We argue that the role of information in HIV/AIDS-related behavior remains ambiguous because the majority of research in this area has measured the effects of one-way mass communication campaigns or health education sessions (Noar et al., 2009) and has failed to account for information behaviors that may take place outside of planned interventions, such as information seeking, incidental information acquisition, and information use. Furthermore, the effects of information provision have been primarily assessed as knowledge change, typically using surveys that assess correct responses to factual questions about HIV/AIDS. However, the information science field has been home to a growing body of research demonstrating that health information acquisition and use have affective and social dimensions (Lee \& Garvin, 2003; Lee, Hwang, Hawkins, \& Pingree, 2008; Nahl, 2007). Yet such an expanded conceptualization of information behavior has heretofore had little influence on health behavior research, including assessment of how people form intentions to engage in health behaviors. Similarly, although information science researchers have focused on the information needs and behaviors of people living with HIV/AIDS (Hogan \& Palmer, 2005; Veinot, 2009), the field has not yet turned much attention to the informational aspects of healthrelated decision making, including how people decide whether and when to get tested for HIV. Therefore, we seek to advance both fields by examining the contribution of information behaviors to predicting health behavior intentions.

In the public health literature, the theory of planned behavior (TPB) provides a model for predicting behavior based on stated intentions to perform the behavior (Ajzen, 1991, 2005). In an analysis of 10 meta-analyses that tested behavior prediction models including the TPB, Sheeran (2002) found a sample-weighted average correlation between intentions and behavior of $.53\left(R^{2}=.28\right)$, within the range of good predictive ability for psychological research. In the TPB model, three belief-based constructs (proximal variables) predict intention: (a) attitude toward the behavior, that is, the individual's beliefs about the behavior and the worth of engaging in it; (b) subjective norms, that is, the level of social pressure the person experiences, especially from people important to him or her, to perform the behavior; and (c) perceived behavioral control (PBC), that is, how easy the person thinks it would be to perform the behavior. The TPB model also includes background factors that can directly influence the proximal predictors of intention. For example, past experience engaging in the behavior is considered to be an informational background factor that can affect attitude (Ajzen \& Fishbein, 2000; Cooke \& Sheeran, 2004) and PBC (Ajzen, 1991).

Large meta-analyses have found good support for application of the TPB model to predicting condom use for preventing transmission of HIV (Albarracín et al., 2005; Sheeran \& Taylor, 1999), but little research has been conducted on HIV testing intentions using the TPB, especially for YMSM. In one study of gay men recruited from two mid-sized northeastern U.S. cities, researchers using the TPB model found that attitude and subjective norms were statistically significant predictors of the intention to get tested for HIV, but perceived behavioral control was not (Rye, Fisher, \& Fisher, 2001). Knussen, Flowers, and Church (2004) surveyed Scottish MSM (mean age $=31.5$ years) and found that attitude was a statistically significant predictor of intention to test, after accounting for age, risky sexual behaviors, and perceived HIV status. They also found that respondents who had tested for HIV in the past were more likely to report intentions to test in the future. Although such studies support use of the TPB for predicting intentions of MSM in general to seek HIV testing, practitioners need a better understanding of younger MSM in particular and their decisions about HIV testing, including the role that health information behavior plays in health behavior intentions.

According to the TPB model, informational constructs such as past experience and level of knowledge have only indirect effects on intention, via the pathways through the proximal predictors. A recent extension of the TPB, the integrated behavioral model (IBM), proposes that these informational constructs can have direct effects on future performance of the behavior (Montaño \& Kasprzyk, 2008). This newer model suggests that knowledge and past behavior may play a more important role than previously recognized in affecting health-related intentions and behavior. At the same time, however, neither model includes information exposure or use as predictors of intention. To investigate the importance of information behaviors, researchers need to measure and analyze those behaviors, not just knowledge scores. This necessitates the creation of models that synthesize the insights of the TPB and IBM 
about the potential importance of knowledge and past behavior but extend these models by including new measures of information exposure and use.

For the present analysis of cross-sectional data gathered from a survey of YMSM, we used the TPB constructs of attitude, subjective norms, and perceived behavioral control, as well as three information behaviors-information exposure, use of information related to HIV testing decisions, and experience obtaining an HIV test-plus self-rating of HIV knowledge to test the following hypotheses:

H1: Adapting the original TPB model to include direct effects of three information behaviors and HIV knowledge will improve the model's ability to predict the intentions of YMSM to seek HIV testing.

H2: Information behaviors will be stronger than HIV knowledge as predictors of HIV testing intentions.

From an information science perspective, a finding that information behaviors are distinct from knowledge and directly affect behavioral intentions could offer the field a critical resource in making the case for the value of information to a health audience.

\section{Methods}

\section{Participants}

We used an online questionnaire to survey YMSM $(N=194)$. Eligibility criteria included identifying as a man who has had sex with other men, being age 18 to 24 , and living in southeastern Michigan (e.g., the metropolitan Detroit area). The current analysis excluded the data from 31 participants who reported that they had either received an HIV-positive test result $(n=15)$ or failed to pick up the results of each HIV test they had taken $(n=17)$. We excluded the first group because people who have received positive test results would primarily receive later blood tests geared toward medical management of HIV (e.g., viral load, CD4 count). The second group might have significant unknown barriers to testing (e.g., more problems with transportation, stronger anxiety about test results) compared with the respondents who received their test results, which might affect the analysis. The small size of each group precluded meaningful statistical analysis on its own. Excluding these two groups resulted in a sample size for this analysis of $N=163$.

\section{Procedures}

Recruitment took place through a variety of venues (e.g., online, health clinics, bars, public postings) targeted to result in an ethnically diverse sample. Participants completed an online self-administered survey after indicating comprehension of the informed consent material and agreement to participate in the study. The survey included questions regarding demographics, HIV testing history and experiences, knowledge and beliefs about HIV, HIV/AIDS-related information acquisition and use patterns, gay community involvement, risk behaviors, and technology use. The survey was pilot-tested and was administered on a dedicated website using Sawtooth software. The survey took 30 to 45 minutes to complete and was distributed to more than 108 screens with an average of six questions per screen; however, skip-response patterns were used, thus reducing survey length for most participants. Participants were able to save in-progress surveys and return later for completion. Participants did not have the opportunity to review their responses, and there were no completeness checks prior to submission. Each participant could select to receive a $\$ 25$ iTunes or Amazon e-gift card for participating.

Web survey data were collected on a secure server under 128-bit SSL encryption and a firewall. After downloading, data were expunged from the server. To prevent multiple entries (Bauermeister et al., 2012), we used participants' e-mail, IP address, browser/operating system, and time taken to complete the survey to flag potential fraudulent/ duplicative cases. We cross-checked e-mail and IP addresses through web applications (e.g., Facebook, IP lookup), without keeping this information or linking it to data. If verified, we treated a case as unique; otherwise, we did not use the entered data. We had 824 unique site visitors, as counted by unique IP addresses. We recorded 1,034 survey entries, which included 194 eligible and complete cases, 16 incomplete entries, and 264 entries that were ineligible for study participation based on eligibility criteria. In addition, we detected 559 fraudulent entries, which were removed from our data set. Our recruitment rate was $79.69 \%$ and, after excluding fraudulent cases, our completion rate was $92.38 \%$. After verification, data were de-identified and transferred into SPSS software (Chicago, IL).

The National Institutes of Health granted a Certificate of Confidentiality, providing assurance to respondents that their identities and information would be safe from disclosure even if requested by subpoena. The Institutional Review Board of the University of Michigan reviewed and approved the study procedures.

\section{Measures}

The key variables used in the analysis are described briefly below.

Intention to seek HIV testing. Participants who responded to the item, "How likely are you to get tested for HIV in the next three months?" chose from the following six options: "Extremely unlikely to get tested," "Very unlikely to get tested," "Somewhat unlikely to get tested," "Somewhat likely to get tested," "Very likely to get tested," or "Extremely likely to get tested."

Information exposure. We created this index of frequency of exposure to HIV/AIDS information by multiplying two other variables to reflect both intentional and incidental exposure to HIV/AIDS information. The first variable, frequency of intentional information acquisition, was a 
one-item measure adapted from the National Cancer Institute's Health Information National Trends Survey (HINTS) (National Cancer Institute, 2007). It is based on respondents' answers to how often in the past 12 months they had looked for HIV/AIDS information from any source, defined as "people, organizations, documents, or the Internet." The second variable, frequency of incidental information acquisition, was a four-item scale developed based on extant theory regarding nonpurposeful information acquisition, including the role of an information-rich environment in facilitating such acquisition (Erdelez, 2005; McKenzie, 2003; Veinot, Harris, Bella, Rootman, \& Krajnak, 2006; Williamson, 2005). For this composite variable, we summed the scores of four items. Respondents answered how much ("Never," "A little," "Some," or "A lot") in the past 12 months they had received HIV/AIDS information in the following ways: "People give me HIV/AIDS information without me asking for it," "I learn unexpected things about HIV/AIDS when I talk to other people," "I learn unexpected things about HIV/AIDS when I watch television or read the newspaper,"

and "I accidentally find information about HIV/AIDS while I look for information about other topics." Reliability for the measure of incidental exposure was acceptable $(\alpha=.768$; $95 \%$ confidence interval $[\mathrm{CI}]=.709-.817)$.

Self-rating of knowledge about HIV testing. Respondents indicated their perception of how much they knew about HIV testing by rating their level of knowledge as "Extremely poor," "Below average," "Average," "Above average," or "Excellent."

Experience using information to make HIV testing decisions. We adopted Kari's (2010) conceptualization of information use as the application of a tool or resource to a given process. The process of interest to us is making decisions that lead to action regarding HIV testing. Similarly, Choo (1996) and Savolainen (2008) highlight decisionmaking as a key form of information use. We asked respondents, "In which of the following ways did you use the HIV/AIDS information that you got in the past 12 months?" and then measured frequency of using information to make decisions related to HIV testing as a summed score of five items: "Decide whether to get tested for HIV," "Decide whether to ask a sexual partner about his/her HIV status," "Decide whether to ask a casual sexual partner to get tested for HIV," "Decide whether to ask a romantic sexual partner to get tested for HIV," and "Find a place to get tested for HIV." The five answer options ranged from "Never" to "Occasionally" to "A great deal." Reliability was good $(\alpha=.926 ; 95 \% \mathrm{CI}=.905-.942)$.

Experience from previous testing. Respondents reported the lifetime number of times they had taken an HIV test and received the results. Due to the skewed nature of this variable, we created a dummy variable with two values: YMSM who had ever completed at least one HIV test and received the results (previous testers) and those who had never had an HIV test (nontesters, the referent group). This variable served as a proxy for whether respondents had gained direct experiential information about HIV testing in the past.

Attitude toward HIV testing. The variable used as an indicator of attitude toward HIV testing was based on respondents' level of agreement with the statement, "Getting an HIV test is the responsible thing to do." Response options were a 5-point Likert-type scale, with "Strongly disagree" as the lowest value, "Undecided" the middle, and "Strongly agree" the highest.

Subjective norms regarding HIV testing. We used a validated, 16-item scale for subjective norms in AIDS prevention (Fisher, Fisher, \& Rye, 1995). The scale included items such as "Most of my friends believe it is important to know your HIV status," "Most people whose opinion I value have encouraged me to get an HIV test," and "My sexual partners expect me to know my HIV status." We computed a summed score for subjective norms from responses about level of disagreement or agreement (4-point scale) on these 16 items. Reliability was good $(\alpha=.915 ; 95 \% \mathrm{CI}=.893-.933)$.

Perceived behavioral control over HIV testing. Perceived behavioral control was operationalized as respondents' reports on a 5-point Likert-type scale of how easy or hard it would be for them to find a location nearby to get an HIV test. Higher values on this variable meant it was easier, that is, more perceived behavioral control over this aspect of HIV testing.

Race and ethnicity (minority). Due to the disproportionate HIV risk among racial minority young men, we created a dummy variable for minority status such that all respondents who reported Latino ethnicity and/or any race other than Caucasian were grouped together. This allowed us to account for racial variability in the sample. Non-Latino Caucasians were the referent group in the statistical analyses.

\section{Data Analytic Strategies}

We used individual and composite variables to explore descriptive statistics about the respondents and their HIV testing and information behaviors. Assumptions for multiple linear regression were met well enough to proceed with analysis of both models of predictors for intention to obtain an HIV test within the next 3 months. Skewness and kurtosis values for the dependent and independent variables were within range for normality, and residuals plots and partial plots looked acceptable. Lack of multicollinearity among the predictors was indicated by all Pearson's correlation measures being $<.7$, variance inflation factor values $<10$, and tolerance values $>.10$. Cook's $d$ values were well below 10 , so no outliers affected the results. For the original TPB model, we first performed multiple regression to determine unique effects of the constructs of interest on the three 
TABLE 1. Sample characteristics: Demographics $(N=163)$.

\begin{tabular}{|c|c|c|c|}
\hline Characteristic & Percentage & $n$ & $\begin{array}{l}\text { Mean }(S D) \text {; } \\
\quad \text { range }\end{array}$ \\
\hline Age & & 163 & $\begin{array}{c}20.5(1.6) \\
18-24\end{array}$ \\
\hline \multicolumn{4}{|l|}{ Race } \\
\hline African American & $49.7 \%$ & 81 & \\
\hline Caucasian & $28.2 \%$ & 46 & \\
\hline $\begin{array}{l}\text { Other single race (Asian, American } \\
\text { Indian or Alaskan Native, Native } \\
\text { Hawaiian or Pacific Islander, or other } \\
\text { specified by participants) }\end{array}$ & $8.6 \%$ & 14 & \\
\hline $\begin{array}{l}\text { Mixed race (combination of two or } \\
\text { more of the previous categories) }\end{array}$ & $13.5 \%$ & 22 & \\
\hline \multicolumn{4}{|l|}{ Ethnicity } \\
\hline Latino (includes Spanish and Hispanic) & $15.3 \%$ & 25 & \\
\hline Non-Latino & $84.7 \%$ & 138 & \\
\hline \multicolumn{4}{|l|}{ Minority or nonminority } \\
\hline $\begin{array}{l}\text { Any minority, including Latino } \\
\text { Caucasians }\end{array}$ & $74.2 \%$ & 121 & \\
\hline Non-Latino Caucasians & $25.8 \%$ & 42 & \\
\hline \multicolumn{4}{|l|}{ Highest level of education } \\
\hline Up to high school or GED & $54.6 \%$ & 89 & \\
\hline Beyond high school & $44.8 \%$ & 73 & \\
\hline \multicolumn{4}{|l|}{ Sexual orientation } \\
\hline Gay or homosexual & $88.3 \%$ & 144 & \\
\hline Bisexual & $9.8 \%$ & 16 & \\
\hline Straight & $2.5 \%$ & 4 & \\
\hline Multiple identifications & $2.5 \%$ & 4 & \\
\hline
\end{tabular}

proximal predictors of intention. We then used those results to determine which paths to include between the background factors and the proximal predictors when conducting recursive path analysis. The technique of path analysis is similar to running a series of multiple regression equations, and it facilitates investigation of relative weights between multiple independent and dependent variables in a model, as well as both direct and indirect effects (Klem, 2000; Kline, 2011). In recursive path analysis, each path is unidirectional, as in our models for predicting intention to seek HIV testing. For the path analysis of the original TPB model, we allowed the variables related to information behavior to have only indirect effects on intention, whereas for the adapted model, information-related variables could have both direct and indirect effects on intention. We used structural equation modeling software (SPSS Amos, v. 20) to perform recursive path analysis with observed variables and to estimate both models. Because of power considerations, sample size did not allow for reliable testing of model fit; therefore, we report fit statistics only briefly in the analyses.

\section{Results}

\section{Descriptives for HIV Testing and Information Behaviors}

Tables 1-4 present the participants' characteristics in terms of demographics, HIV-related sexual behaviors, information behaviors, and TPB constructs, respectively. The
TABLE 2. Sample characteristics: Sexual behaviors.

\begin{tabular}{|c|c|c|c|}
\hline Characteristic & Percentage & $n$ & $\begin{array}{l}\text { Mean }(S D) ; \\
\text { range }\end{array}$ \\
\hline \multicolumn{4}{|l|}{$\begin{array}{l}\text { Reported risky sexual behaviors in the } \\
\text { past } 2 \text { months (URAI = unprotected } \\
\text { receptive anal intercourse; } \\
\text { UIAI }=\text { unprotected insertive anal } \\
\text { intercourse) }\end{array}$} \\
\hline Neither URAI nor UIAI & $66.3 \%$ & 108 & \\
\hline UIAI but not URAI & $10.4 \%$ & 17 & \\
\hline URAI but not UIAI & $8.0 \%$ & 13 & \\
\hline Both UIAI and URAI & $15.3 \%$ & 25 & \\
\hline \multicolumn{4}{|l|}{ Past HIV testing experience } \\
\hline Number of times tested in the past & & 163 & $\begin{array}{c}2.53(3.24) \\
0-16\end{array}$ \\
\hline Have never tested (nontesters) & $39.9 \%$ & 65 & \\
\hline $\begin{array}{l}\text { Have tested and received results at } \\
\text { least one time (previous testers) }\end{array}$ & $60.1 \%$ & 98 & \\
\hline
\end{tabular}

TABLE 3. Sample characteristics: Information behaviors.

\begin{tabular}{|c|c|c|c|}
\hline Characteristic & Percentage & $n$ & $\begin{array}{l}\text { Mean }(S D) \text {; } \\
\quad \text { range }\end{array}$ \\
\hline $\begin{array}{l}\text { Frequency of intentionally seeking } \\
\text { HIV/AIDS information from any } \\
\text { source within past } 12 \text { months }\end{array}$ & & 163 & $\begin{array}{l}2.91(1.18) \\
1-5\end{array}$ \\
\hline Never & $14.7 \%$ & 24 & \\
\hline Rarely & $19.0 \%$ & 31 & \\
\hline Sometimes & $38.0 \%$ & 62 & \\
\hline Often & $17.2 \%$ & 28 & \\
\hline Very often & $11.0 \%$ & 18 & \\
\hline $\begin{array}{l}\text { Frequency of incidentally receiving } \\
\text { HIV/AIDS information from any } \\
\text { source within past } 12 \text { months }\end{array}$ & & 163 & $\begin{array}{l}8.93(3.10) \\
\quad 4-16\end{array}$ \\
\hline $\begin{array}{l}\text { Index of total exposure to HIV/AIDS } \\
\text { information within past } 12 \text { months }\end{array}$ & & 163 & $\begin{array}{c}26.83(15.50) \\
4-80\end{array}$ \\
\hline $\begin{array}{l}\text { Self-rating of level of HIV testing } \\
\text { knowledge }\end{array}$ & & 163 & $\begin{array}{c}3.63(1.17) \\
1-5\end{array}$ \\
\hline $\begin{array}{l}\text { Frequency of using information to make } \\
\text { decisions related to HIV testing } \\
\text { within past } 12 \text { months }\end{array}$ & & 163 & $\begin{array}{c}15.98(6.10) \\
5-25\end{array}$ \\
\hline
\end{tabular}

mean age was 20.5 years ( $S D=1.6$ years). Almost half the sample was African American $(49.7 \%, n=81)$. The mean number of times tested for HIV was $2.53(S D=3.24)$, with $39.9 \%(n=65)$ of the sample reporting no prior HIV testing. Regarding how likely they thought they were to get tested in the next 3 months, $73.2 \%(n=121)$ indicated that it was either somewhat, very, or extremely likely, and $25.8 \%$ $(n=42)$ indicated that it was either somewhat, very, or extremely unlikely (Table 4). The sample mean of 3.97 $(S D=1.34)$ corresponded to being somewhat likely to get tested within 3 months.

\section{Estimation of Original Model for Intention to Seek HIV Testing}

Table 5 shows the Pearson correlations between the information behavior variables. Correlations were found 
TABLE 4. Sample characteristics: TPB constructs.

\begin{tabular}{|c|c|c|c|}
\hline Characteristic & Percentage & $n$ & $\begin{array}{l}\text { Mean }(S D) \\
\quad \text { range }\end{array}$ \\
\hline Attitude toward HIV testing & & 163 & $\begin{array}{c}4.47(0.76) \\
1-5\end{array}$ \\
\hline Subjective norms regarding HIV testing & & 163 & $\begin{array}{c}46.18(8.67) ; \\
22-64\end{array}$ \\
\hline $\begin{array}{l}\text { Perceived behavioral control over HIV } \\
\text { testing }\end{array}$ & & 162 & $\begin{array}{c}4.15(0.95) \\
1-5\end{array}$ \\
\hline $\begin{array}{l}\text { Intention to get tested within next } 3 \\
\text { months }\end{array}$ & & 163 & $\begin{array}{c}3.97(1.34) \\
1-6\end{array}$ \\
\hline Extremely unlikely to get tested & $7.4 \%$ & 12 & \\
\hline Very unlikely to get tested & $8.0 \%$ & 13 & \\
\hline Somewhat unlikely to get tested & $10.4 \%$ & 17 & \\
\hline Somewhat likely to get tested & $40.5 \%$ & 66 & \\
\hline Very likely to get tested & $22.1 \%$ & 36 & \\
\hline Extremely likely to get tested & $11.7 \%$ & 19 & \\
\hline
\end{tabular}

TABLE 5. Bivariate Pearson correlations for the information behaviors.

\begin{tabular}{|c|c|c|c|c|}
\hline Variables & 1 & 2 & 3 & 4 \\
\hline $\begin{array}{l}\text { 1. Frequency of overall exposure to } \\
\text { information (intentional and } \\
\text { incidental) }\end{array}$ & - & & & \\
\hline $\begin{array}{l}\text { 2. Self-rating of knowledge about HIV } \\
\text { testing }\end{array}$ & $.380 * *$ & - & & \\
\hline $\begin{array}{l}\text { 3. Frequency of using information to } \\
\text { make decisions related to HIV testing }\end{array}$ & $.485^{* * *}$ & $.419 * *$ & - & \\
\hline 4. Previous testers & .103 & $.312 * *$ & .116 & - \\
\hline
\end{tabular}

$* * p<.01$ (two-tailed).

between information exposure and information use to make decisions about HIV testing $(r=.485)$, between information use and self-rating of HIV testing knowledge $(r=.419)$, and between information exposure and self-rating of knowledge $(r=.380)$. Self-rating of knowledge was also associated with experience of an HIV test in the past $(r=.312)$.

Preliminary multiple regression of each of the three proximal predictors for intention on the information behavior variables revealed statistically significant associations for each information variable. Compared with non-Latino Caucasians (the referent group), respondents with minority heritage (race or ethnicity) did not differ significantly on any of the predictors for intention after accounting for the four information-related variables. Since the minority variable did not have a statistically significant association with any of the original TPB predictors on intention to test, race and ethnicity were excluded from further analysis. Regression results were used to determine which paths between informational background factors and proximal predictors of intention to include in the original TPB model (Figure 1). Modification indices of the initial path analysis indicated that unobserved variables e 3 (the residuals term on subjective norms) and e4 (the residuals term on perceived behavioral control) had a moderate covariance $(r=.35, p=.001)$.
This covariance was added to the model because the unexplained residuals of subjective norms and perceived behavioral control could have a strong correlation due to the idea that information gained through communicating with others about their beliefs and experiences can affect development of PBC (Ajzen, 1991).

As estimated through path analysis, each of the information-related variables was associated with at least one of the proximal predictors of intention (Table 6). Self-rating of HIV testing knowledge was associated with all three proximal predictors. The estimated original model explained $18.1 \%$ of the variance in intention to test. Only one proximal predictor had a statistically significant correlation with intention after controlling for the other two predictors: attitude toward HIV testing was positively associated with intent to obtain an HIV test $(\beta=.339, p<.01)$. Two of the information behavior variables also had small but significant indirect effects on intention to test: self-rating of knowledge $(\beta=.156, p<.01)$ and use of information to make testing decisions $(\beta=.095, p<.01)$. Fit statistics, reported for completeness rather than model testing due to power limitations, were poor, $\chi^{2}(12)=79.368, p<.001$; Comparative Fit Index $(\mathrm{CFI})=.834$; Root Mean Square Error of Approximation $($ RMSEA $)=.186$, with $90 \% \mathrm{CI}=.148-.226$.

\section{Estimation of Adapted Model for Intention to Seek HIV Testing}

Simultaneous multiple regression of intention to test on the information behavior variables and proximal predictors from the original model revealed statistically significant unique associations between intention and three of the information behavior variables (information exposure, information use, and experience of prior testing). Therefore, paths linking these variables directly to intent to test were added to the original model to create the adapted model (Figure 2). Self-rating of HIV testing knowledge was not uniquely significant after accounting for the other variables and thus only its indirect effects on intention were included in the adapted model.

The adapted model explained $41.9 \%$ of the variance in intention to test, more than twice that for the original model. After accounting for attitude, subjective norms, and perceived behavioral control, as shown in Table 7, all three information behaviors had significant direct effects on intent: experience getting tested $(\beta=.444, p<.01)$, use of information to make testing decisions $(\beta=.213, p<.01)$, and information exposure $(\beta=.192, p<.05)$. These coefficients were larger than those for the usual TPB predictors of intention. Attitude continued to have a unique effect, although its standardized $\beta$ and significance level decreased compared with the first model $(\beta=.179$ and $p<.05$ vs. $\beta=.339$ and $p<.01$, respectively). In the adapted model, perceived behavioral control became significant at the $p<.05$ level, with a negative standardized $\beta=-.171$. Fit statistics were marginal, $\chi^{2}(9)=22.787, p<.01 ; \mathrm{CFI}=.966$; RMSEA $=.097$, with $90 \% \mathrm{CI}=.048-.148$. 


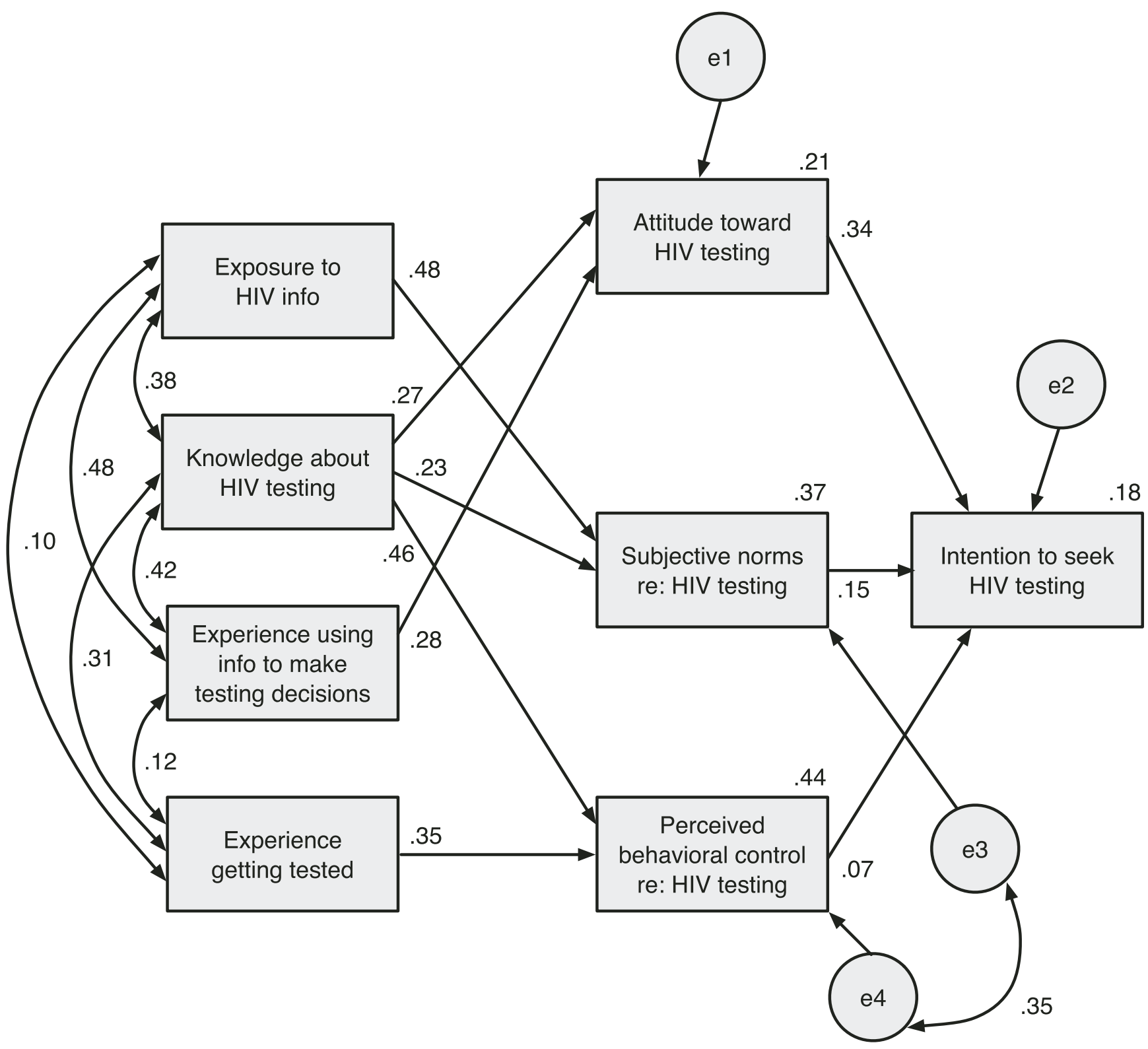

FIG. 1. Path diagram of the estimated portion of the original model, with standardized coefficients. All path coefficients were statistically significant at the $p<.01$ level in this estimated model except two that were not significant (subjective norms $\rightarrow$ intention and perceived behavioral control $\rightarrow$ intention). $R^{2}=.181$ for intention to seek HIV testing.

\section{Discussion}

We hypothesized that including direct effects of three information behaviors (information exposure, use of information related to HIV testing decisions, and experience obtaining an HIV test) and self-rating of HIV knowledge on the intentions of YMSM to seek HIV testing would have greater predictive ability than the original TPB model. Our results partially supported this hypothesis: The adapted model including direct effects of information exposure, use, and experience explained more than twice as much of the variance in intention when compared with the original model, but self-rated knowledge did not directly affect intention. Further supporting our belief about the importance of information behaviors, the standardized regression coeffi- cients were larger for information exposure, use, and experience than for the original TPB proximal predictors of intention (attitude, subjective norms, and PBC). Because knowledge was not directly associated with intention to seek HIV testing, our results also supported our hypothesis that information behaviors would be stronger predictors of intention than knowledge would be.

Our findings suggest that information behaviors may have important effects on the formation of health behavior intentions that are not acknowledged in the theory of planned behavior - one of the most widely used psychosocial models of behavior in the public health field. Recent additions to the TPB, as outlined in the integrated behavioral model (Montaño \& Kasprzyk, 2008), indicate that inclusion 
TABLE 6. Standardized total, direct, and indirect path coefficients for the original model.

\begin{tabular}{|c|c|c|c|c|c|c|}
\hline \multirow[b]{2}{*}{ Path } & \multicolumn{2}{|c|}{ Standardized total effects } & \multicolumn{2}{|c|}{ Standardized direct effects } & \multicolumn{2}{|c|}{ Standardized indirect effects } \\
\hline & $\begin{array}{l}\text { Estimate } \\
(90 \% \mathrm{CI})\end{array}$ & $p$ value & $\begin{array}{l}\text { Estimate } \\
(90 \% \mathrm{CI})\end{array}$ & $p$ value & $\begin{array}{l}\text { Estimate } \\
(90 \% \mathrm{CI})\end{array}$ & $p$ value \\
\hline Info exposure $\rightarrow$ subjective norms & $\begin{array}{c}.482 \\
(.382-.577)\end{array}$ & .001 & $\begin{array}{c}.482 \\
(.382-.577)\end{array}$ & .001 & - & - \\
\hline Info exposure $\rightarrow$ intent to test & $\begin{array}{c}.072 \\
(.011-.147)\end{array}$ & .058 & - & - & $\begin{array}{c}.072 \\
(.011-.147)\end{array}$ & .058 \\
\hline Knowledge $\rightarrow$ attitude & $\begin{array}{c}.267 \\
(.135-.384)\end{array}$ & .001 & $\begin{array}{c}.267 \\
(.135-.384)\end{array}$ & .001 & - & - \\
\hline Knowledge $\rightarrow$ subjective norms & $\begin{array}{c}.226 \\
(.111-.334)\end{array}$ & .002 & $\begin{array}{c}.226 \\
(.111-.334)\end{array}$ & .002 & - & - \\
\hline Knowledge $\rightarrow$ perceived behavioral control & $\begin{array}{c}.465 \\
(.356-.555)\end{array}$ & .001 & $\begin{array}{c}.465 \\
(.356-.555)\end{array}$ & .001 & - & - \\
\hline Knowledge $\rightarrow$ intent to test & $\begin{array}{c}.156 \\
(.086-.232)\end{array}$ & .001 & - & - & $\begin{array}{c}.156 \\
(.086-.232)\end{array}$ & .001 \\
\hline Info use $\rightarrow$ attitude & $\begin{array}{c}.279 \\
(.148-.397)\end{array}$ & .001 & $\begin{array}{c}.279 \\
(.148-.397)\end{array}$ & .001 & - & - \\
\hline Info use $\rightarrow$ intent to test & $\begin{array}{c}.095 \\
(.042-.160)\end{array}$ & .001 & - & - & $\begin{array}{c}.095 \\
(.042-.160)\end{array}$ & .001 \\
\hline Previous test $\rightarrow$ perceived behavioral control & $\begin{array}{c}.353 \\
(.259-.454)\end{array}$ & .001 & $\begin{array}{c}.353 \\
(.259-.454)\end{array}$ & .001 & - & - \\
\hline Previous test $\rightarrow$ intent to test & $\begin{array}{c}.024 \\
(-.020-.081)\end{array}$ & .380 & - & - & $\begin{array}{c}.024 \\
(-.020-.081)\end{array}$ & .380 \\
\hline Attitude $\rightarrow$ intent to test & $\begin{array}{c}.339 \\
(.217-.458)\end{array}$ & .001 & $\begin{array}{c}.339 \\
(.217-.458)\end{array}$ & .001 & - & - \\
\hline Subjective norms $\rightarrow$ intent to test & $\begin{array}{c}.150 \\
(.020-.280)\end{array}$ & .067 & $\begin{array}{c}.150 \\
(.020-.280)\end{array}$ & .067 & - & - \\
\hline Perceived behavioral control $\rightarrow$ intent to test & $\begin{array}{c}.068 \\
(-.065-.201)\end{array}$ & .394 & $\begin{array}{c}.068 \\
(-.065-.201)\end{array}$ & .394 & - & - \\
\hline
\end{tabular}

of information-related constructs (e.g., knowledge, experience) improve the model's predictive ability. Consistent with Sligo and Jameson (2000), our findings suggest that there seems to be a knowledge-behavior gap. Knowledge was found to be associated with participants' attitudes, subjective norms, and perceived behavioral control to get tested for HIV; however, knowledge was not associated with HIV testing intentions. These findings suggest that conceptualizing knowledge is important yet not sufficient to represent the total effects of information on intentions and behavior. From a practice standpoint, these findings underscore the importance of providing YMSM with HIV-related knowledge as a strategy to facilitate positive beliefs about HIV testing; however, knowledge alone is insufficient to motivate their testing intentions.

We conceptualize information behavior to also include information exposure, use, and experience. We contend that attempting to measure and analyze the effects of health information simply in terms of participants' knowledge overlooks the potential contributions of information behaviors, especially in two intertwined areas: (a) individuals' perceptions of the relevance of specific health information to their own lives, and (b) social interactions within everyday life that may contextualize the information and motivate health decision making. For example, information exposure could result from YMSM's pursuit of information that was relevant to their lives, as well as by incidental acquisition of information from their social networks. Consistent with this perspective, we found that information exposure was positively and directly associated with their HIV testing intentions, as well as indirectly through subjective norms (i.e., important people in YMSM's lives would want them to be aware of their HIV status). These findings highlight the importance of acknowledging the social embeddedness of health information exchange and point toward the need to facilitate opportunities for YMSM to apply the information they receive into their own social context and actively integrate it into their lives. Taken together, these findings suggest that HIV/AIDS interventions should develop opportunities for YMSM to identify their own perceived needs, to look for the information they feel is relevant to their lives, and to share obtained information with others.

When health information is integrated into the flow of everyday life, including valued social interactions, individuals may perceive the acquired information to be more relevant to their own needs and may thus be more likely to use it to make decisions (Henwood, Harris, \& Spoel, 2011; McKenzie, 2003). Consistent with this perspective, we found that information use was positively associated with HIV testing attitudes and intentions, respectively, particularly if it helped YMSM decide whether and how to ask casual or romantic sexual partners to reveal the results of past HIV tests or to get a new HIV test—situations in which both information relevance and social interactions come into 


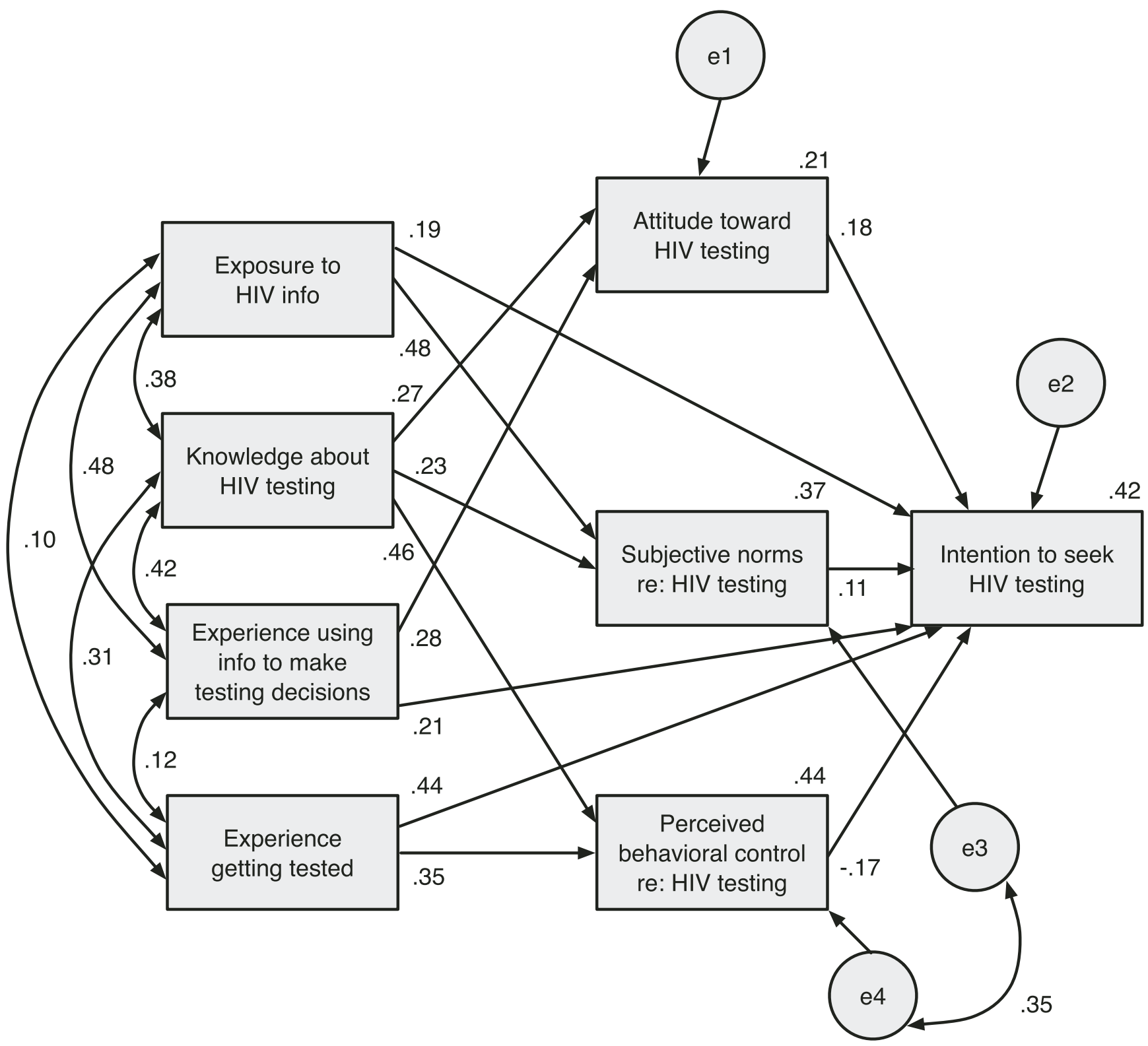

FIG. 2. Path diagram of the estimated portion of the adapted model, with standardized coefficients. All path coefficients were statistically significant at the $p<.01$ level in this estimated model except three that were significant at $p<.05$ (information exposure $\rightarrow$ intention, attitude $\rightarrow$ intention, and perceived behavioral control $\rightarrow$ intention) and one that was not significant (subjective norms $\rightarrow$ intention). $R^{2}=.419$ for intention to seek HIV testing.

play. Based on these results, we assert that researchers need to create and test models that go beyond the TPB and IBM by including the emotional and social effects of information behaviors (Lee \& Garvin, 2003; Lee et al., 2008; Nahl, 2007). For example, in the context of decision-making about HIV/AIDS, the interactive processes by which people acquire and use information may include elements of social support (Gustafson et al., 1999; Veinot, 2009) as well as social influence. Our finding of a strong, positive association between information exposure and subjective norms (see Tables 6 and 7) appears to support this assertion. Thus, considering our findings, we contend that including information behaviors in models of health behavior change would offer a more robust framework for predicting, understanding, and potentially influencing the intentions of YMSM to seek HIV testing than either the TPB or IBM. Further research is needed to investigate the unique contributions of information behaviors and how they might be leveraged through information systems and services that focus on relevance and social interactions within everyday life, moving beyond mass media and practitioner-based health education campaigns. For example, researchers could examine how such factors as partnership type and interpersonal dynamics may influence YMSM's exposure to and use of HIV testing information.

Consistent with prior research, we noted that past behavior was a strong predictor of intention (Ajzen, 2002; Conner \& Armitage, 1998; Knussen et al., 2004; Sheeran, 2002). 
TABLE 7. Standardized total, direct, and indirect path coefficients for the adapted model.

\begin{tabular}{|c|c|c|c|c|c|c|}
\hline \multirow[b]{2}{*}{ Path } & \multicolumn{2}{|c|}{ Standardized total effects } & \multicolumn{2}{|c|}{ Standardized direct effects } & \multicolumn{2}{|c|}{ Standardized indirect effects } \\
\hline & $\begin{array}{l}\text { Estimate } \\
(90 \% \mathrm{CI})\end{array}$ & $p$ value & $\begin{array}{l}\text { Estimate } \\
(90 \% \mathrm{CI})\end{array}$ & $p$ value & $\begin{array}{l}\text { Estimate } \\
(90 \% \mathrm{CI})\end{array}$ & $p$ value \\
\hline Info exposure $\rightarrow$ subjective norms & $\begin{array}{c}.482 \\
(.382-.577)\end{array}$ & .001 & $\begin{array}{c}.482 \\
(.382-.577)\end{array}$ & .001 & - & - \\
\hline Info exposure $\rightarrow$ intent to test & $\begin{array}{c}.245 \\
(.120-.357)\end{array}$ & .002 & $\begin{array}{c}.192 \\
(.063-.321)\end{array}$ & .012 & $\begin{array}{c}.053 \\
(-.014-.124)\end{array}$ & .175 \\
\hline Knowledge $\rightarrow$ attitude & $\begin{array}{c}.267 \\
(.135-.384)\end{array}$ & .001 & $\begin{array}{c}.267 \\
(.135-.384)\end{array}$ & .001 & - & - \\
\hline Knowledge $\rightarrow$ subjective norms & $\begin{array}{c}.226 \\
(.111-.334)\end{array}$ & .002 & $\begin{array}{c}.226 \\
(.111-.334)\end{array}$ & .002 & - & - \\
\hline Knowledge $\rightarrow$ perceived behavioral control & $\begin{array}{c}.465 \\
(.356-.555)\end{array}$ & .001 & $\begin{array}{c}.465 \\
(.356-.555)\end{array}$ & .001 & - & - \\
\hline Knowledge $\rightarrow$ intent to test & $\begin{array}{c}-.007 \\
(-.075-.059)\end{array}$ & .840 & - & - & $\begin{array}{c}-.007 \\
(-.075-.059)\end{array}$ & .840 \\
\hline Info use $\rightarrow$ attitude & $\begin{array}{c}.279 \\
(.148-.397)\end{array}$ & .001 & $\begin{array}{c}.279 \\
(.148-.397)\end{array}$ & .001 & - & - \\
\hline Info use $\rightarrow$ intent to test & $\begin{array}{c}.263 \\
(.135-.377)\end{array}$ & .002 & $\begin{array}{c}.213 \\
(.086-.332)\end{array}$ & .002 & $\begin{array}{c}.050 \\
(.017-.096)\end{array}$ & .010 \\
\hline Previous test $\rightarrow$ perceived behavioral control & $\begin{array}{c}.353 \\
(.259-.454)\end{array}$ & .001 & $\begin{array}{c}.353 \\
(.259-.454)\end{array}$ & .001 & - & - \\
\hline Previous test $\rightarrow$ intent to test & $\begin{array}{c}.384 \\
(.270-.471)\end{array}$ & .002 & $\begin{array}{c}.444 \\
(.319-.545)\end{array}$ & .002 & $\begin{array}{c}-.060 \\
(-.116--.017)\end{array}$ & .022 \\
\hline Attitude $\rightarrow$ intent to test & $\begin{array}{c}.179 \\
(.071-.293)\end{array}$ & .015 & $\begin{array}{c}.179 \\
(.071-.293)\end{array}$ & .015 & - & - \\
\hline Subjective norms $\rightarrow$ intent to test & $\begin{array}{c}.111 \\
(-.034-.253)\end{array}$ & .191 & $\begin{array}{c}.111 \\
(-.034-.253)\end{array}$ & .191 & - & - \\
\hline Perceived behavioral control $\rightarrow$ intent to test & $\begin{array}{c}-.171 \\
(-.295--.044)\end{array}$ & .029 & $\begin{array}{c}-.171 \\
(-.295--.044)\end{array}$ & .029 & - & - \\
\hline
\end{tabular}

Furthermore, YMSM who reported prior HIV testing experiences were also more likely to report having greater confidence in their ability to get tested for HIV again (see Tables 6 and 7). Given these strong relationships, an important implication of this study is the need to develop and study interventions that could help YMSM complete an HIV test for the first time. Creating interactive interventions that help YMSM process information to make realistic risk appraisals and to handle any fears they might have about sexual risks and HIV (Fisher \& Misovich, 1990; Gold \& Karantzas, 2008; Lelutiu-Weinberger et al., 2011) may help encourage YMSM to test earlier in their lifecourse. For example, community-based or social-network approaches in which past testers could share their HIV testing experiences with nontesters while providing support for information acquisition and use could be helpful. In addition, further research is needed to determine the role that experiential information (Veinot, 2010) plays with respect to how people appropriate HIV/AIDS information learned in the past into new contexts (e.g., changes in partners, social networks, risk factors) as it may affect HIV testing decisions.

Our findings about the importance of information behaviors may be particularly salient in the context of recent FDA approval of home-based rapid HIV testing. YMSM who seek HIV testing in the future will not always do so through healthcare providers or AIDS service organizations, as in the past. In this new context, information expo- sure, use, and experience are likely to be more important testing influences than ever, taking place outside of institutional contexts and within everyday life, particularly as individuals will have more agency over their HIV testing and will be able to receive real-time information that could affect their decisions about engaging in risky sexual behaviors with particular partners (Carballo-Diéguez et al., 2012). This opens the door to new research into in-themoment interventions about HIV testing, including how to help YMSM negotiate the use of home-based rapid HIV tests with potential partners. We note that although rapid HIV testing at clinics has helped reduce barriers to picking up HIV test results and rapid in-home testing will likely also increase the number of people who learn their serostatus, $25 \%$ of the YMSM in a recent study reported concerns about the emotional impacts of receiving results so quickly, feeling unprepared to deal with the potential consequences (Cohall et al., 2010). This emotional aspect may similarly affect YMSM who consider using rapid HIV home testing kits. Further research is needed to develop theoretical models for the complex interactions between affective and information behaviors in community contexts (Veinot, Meadowbrooke, Loveluck, Hickok, \& Bauermeister, 2013) and to guide the design of interventions intended to help people make and maintain health behavior changes (Rothman, 2000), especially in this new context of rapid in-home HIV testing. 
Our study had some limitations. The variables for attitude and perceived behavioral control were based on singlerather than multi-item scores, which may help explain the unexpected negative relationship in the adapted model between PBC and intention to seek HIV testing. Further study with stronger measures for these constructs is needed. Also, given the established social norms regarding HIV testing, measurement error likely exists due to social desirability bias. If such bias holds, respondents would tend to overreport the number of past HIV tests and intentions to seek future testing. The anonymous, self-administered online data collection likely helped reduce some of that bias (Groves et al., 2009). Another limitation is that the cross-sectional design did not allow for follow-up to determine whether reported intentions accurately predicted behavior. Future longitudinal research including measures of whether participants obtained HIV testing would be useful to investigate the direct effects of information behaviors on HIV testing decisions. Finally, further research is needed through offline survey modes and in other geographical areas to assess the generalizability of this study's findings to the larger YMSM community. Future research with large enough samples to complete subgroup analyses according to whether a participant has had an HIV test in the past, and whether he picked up his results, would also be valuable.

Despite these limitations, this study is one of the first to examine the direct effects of information behaviors on HIV testing decisions made by YMSM, and the results suggest several promising avenues for future research and interventions. Our research also begins to lay the foundation for an interesting new area of research: investigating the role of information behaviors in health behavior formation and change. This line of research has the potential for informing new forms of information practice and for better assessing the impact of our efforts.

\section{Conclusion}

This study indicates that modeling the information behaviors of exposure, use, and experience as direct predictors of the intentions of YMSM to seek HIV testing can create a more robust framework for predicting, understanding, and influencing the intentions of YMSM to seek HIV testing. Information behaviors are more interactive and socially embedded than previously recognized, possibly accounting for their significant effects on HIV testing intentions. To enrich models related to HIV testing, we must use a more expanded definition of information that focuses on the effects of information behaviors rather than simply equating information with knowledge. Having a more accurate model of intention could improve the design and evaluation of interventions to promote HIV testing, especially to help young men manage the transition to completing their first HIV test, whether at a clinic or on their own with one of the newly FDA-approved in-home rapid testing kits. Finding better ways to support YMSM in creating commitments to regular HIV testing and sexual health in general could help further reduce HIV transmission rates and decrease the personal and societal burdens of living with HIV/AIDS.

\section{Acknowledgments}

This project was funded by the National Institutes of Health, National Center for Research Resources, Grant UL1RR024986. Dr. Bauermeister is supported by a Career Development Award from the National Institute of Mental Health (K01-MH087242). The views expressed in this article do not necessarily represent the views of the funding agencies.

\section{References}

Ajzen, I. (1991). The theory of planned behavior. Organizational Behavior and Human Decision Processes, 50(2), 179-211.

Ajzen, I. (2002). Residual effects of past on later behavior: Habituation and reasoned action perspectives. Personality and Social Psychology Review, $6(2), 107-122$.

Ajzen, I. (2005). Attitudes, personality, and behavior. Berkshire, UK: Open University Press.

Ajzen, I., \& Fishbein, M. (2000). Attitudes and the attitude-behavior relation: Reasoned and automatic processes. European Review of Social Psychology, 11(1), 1-33.

Albarracín, D., Gillette, J.C., Earl, A.N., Glasman, L.R., Durantini, M.R., \& Ho, M. (2005). A test of major assumptions about behavior change: A comprehensive look at the effects of passive and active HIV-prevention interventions since the beginning of the epidemic. Psychological Bulletin, 131(6), 856-897.

Baldwin, J.I., Whiteley, S., \& Baldwin, J.D. (1990). Changing AIDS- and fertility-related behavior: The effectiveness of sexual education. Journal of Sex Research, 27(2), 245-263.

Bauermeister, J., Pingel, E., Zimmerman, M., Couper, M., Carballo-Diéguez, A., \& Strecher, V.J. (2012). Data quality in web-based HIV/AIDS research: Handling invalid and suspicious data. Field Methods, 24(3), 272-291.

Bowles, K.E., Clark, H.A., Tai, E., Sullivan, P.S., Song, B., Tsang, J., . . . Heffelfinger, J.D. (2008). Implementing rapid HIV testing in outreach and community settings: Results from an Advancing HIV Prevention demonstration project conducted in seven U.S. cities. Public Health Reports, 123(Suppl 3), 78-85.

Carballo-Diéguez, A., Frasca, T., Balan, I., Ibitoye, M., \& Dolezal, C. (2012). Use of a rapid HIV home test prevents HIV exposure in a high risk sample of men who have sex with men. AIDS and Behavior (Aug. 15), 1-8.

Centers for Disease Control and Prevention. (2003). Advancing HIV prevention: New strategies for a changing epidemic-United States, 2003. MMWR. Morbidity and Mortality Weekly Report, 52(15), 329-332.

Choo, C.W. (1996). The knowing organization: How organizations use information to construct meaning, create knowledge and make decisions. International Journal of Information Management, 16(5), 329-340.

Cohall, A., Dini, S., Nye, A., Dye, B., Neu, N., \& Hyden, C. (2010). HIV testing preferences among young men of color who have sex with men. American Journal of Public Health, 100(10), 1961-1966.

Conner, M., \& Armitage, C.J. (1998). Extending the theory of planned behavior: A review and avenues for further research. Journal of Applied Social Psychology, 28(15), 1429-1464.

Cooke, R., \& Sheeran, P. (2004). Moderation of cognition-intention and cognition-behaviour relations: A meta-analysis of properties of variables from the theory of planned behaviour. British Journal of Social Psychology, 43(2), 159-186.

El-Sadr, W.M., Mayer, K.H., \& Hodder, S.L. (2010). AIDS in AmericaForgotten but not gone. New England Journal of Medicine, 362(11), 967-970. 
Erdelez, S. (2005). Information encountering. In K.E. Fisher, S. Erdelez, \& E.F. McKechnie (Eds.), Theories of information behavior: A researcher's guide (pp. 179-184). Medford, NJ: Information Today.

Fisher, J.D., \& Fisher, W.A. (1992). Changing AIDS-risk behavior. Psychological Bulletin, 111(3), 455-474.

Fisher, J.D., \& Misovich, S.J. (1990). Evolution of college students' AIDSrelated behavioral responses, attitudes, knowledge, and fear. AIDS Education and Prevention, 2(4), 322-337.

Fisher, W.A., Fisher, J.D., \& Rye, B.J. (1995). Understanding and promoting AIDS-preventive behavior: Insights from the theory of reasoned action. Health Psychology, 14(3), 255-264.

Gold, R.S., \& Karantzas, G. (2008). Thought processes associated with reluctance in gay men to be tested for HIV. International Journal of STD \& AIDS, 19(11), 775-779.

Groves, R.M., Fowler Jr., F.J., Couper, M.P., Lepkowski, J.M., Singer, E., \& Tourangeau, R. (2009). Survey methodology (2nd ed.). Hoboken, NJ: Wiley.

Gustafson, D.H., Hawkins, R., Boberg, E., Pingree, S., Serlin, R.E., Graziano, F., \& Chan, C.L. (1999). Impact of a patient-centered, computer-based health information/support system. American Journal of Preventive Medicine, 16(1), 1-9.

Hall, H.I., Byers, R.H., Ling, Q., \& Espinoza, L. (2007). Racial/ethnic and age disparities in HIV prevalence and disease progression among men who have sex with men in the United States. American Journal of Public Health, 97(6), 1060-1066.

Henwood, F., Harris, R., \& Spoel, P. (2011). Informing health? Negotiating the logics of choice and care in everyday practices of "healthy living." Social Science and Medicine, 72(12), 2026-2032.

Hogan, T.P., \& Palmer, C.L. (2005). Information preferences and practices among people living with HIV/AIDS: Results from a nationwide survey. Journal of the Medical Library Association, 93(4), 431-439.

Holtgrave, D.R., \& Curran, J.W. (2006). What works, and what remains to be done, in HIV prevention in the United States. Annual Review of Public Health, 27(1), 261-275.

Kari, J. (2010). Diversity in the conceptions of information use. Information Research, 15(3), colis709.

Kellerman, S.E., Lehman, S.J., Lansky, A., Stevens, M.R., Hecht, F.M., Bindman, A.B., \& Wortley, P.M. (2002). HIV testing within at-risk populations in the United States and the reasons for seeking or avoiding HIV testing. Journal of Acquired Immune Deficiency Syndromes, 31(2), 202-210.

Klem, L. (2000). Path analysis. In L.G. Grimm \& P.R. Yarnold (Eds.), Reading and understanding multivariate statistics (pp. 65-97). Washington, DC: American Psychological Association.

Kline, R.B. (2011). Principles and practice of structural equation modeling (3rd ed.). New York: Guilford Press.

Knussen, C., Flowers, P., \& Church, S. (2004). The intentions of gay men in taking an HIV test. Culture, Health \& Sexuality, 6(1), 45-59.

Lee, R.G., \& Garvin, T. (2003). Moving from information transfer to information exchange in health and health care. Social Science \& Medicine, 56(3), 449-464.

Lee, S.Y., Hwang, H., Hawkins, R., \& Pingree, S. (2008). Interplay of negative emotion and health self-efficacy on the use of health information and its outcomes. Communication Research, 35(3), 358-381.

Lelutiu-Weinberger, C., Pachankis, J., Golub, S., Walker, J., Bamonte, A., \& Parsons, J. (2011). Age cohort differences in the effects of gay-related stigma, anxiety and identification with the gay community on sexual risk and substance use. AIDS and Behavior, 1-10.

MacKellar, D.A., Valleroy, L.A., Secura, G.M., Behel, S., Bingham, T., Celentano, D.D., \& Young Men's Survey Study Group. (2005). Unrecognized HIV infection, risk behaviors, and perceptions of risk among young men who have sex with men: Opportunities for advancing HIV prevention in the third decade of HIV/AIDS. Journal of Acquired Immune Deficiency Syndromes, 38(5), 603-614.

McKenzie, P.J. (2003). A model of information practices in accounts of everyday-life information seeking. Journal of Documentation, 59(1), $19-40$.
Montaño, D.E., \& Kasprzyk, D. (2008). Theory of reasoned action, theory of planned behavior, and the integrated behavioral model. In K. Glanz, B.K. Rimer, \& K. Viswanath (Eds.), Health behavior and health education: Theory, research, and practice (pp. 67-96). San Francisco, CA: Jossey-Bass.

Nahl, D. (2007). The centrality of the affective in information behavior. In D. Nahl \& D. Bilal (Eds.), Information and emotion: The emergent affective paradigm in information behavior research and theory (pp. 3-37). Medford, NJ: Information Today.

National Cancer Institute. (2007). All HINTS questions. Retrieved from http://hints.cancer.gov/questions.aspx

Noar, S.M., Palmgreen, P., Chabot, M., Dobransky, N., \& Zimmerman, R.S. (2009). A 10-year systematic review of HIV/AIDS mass communication campaigns: Have we made progress? Journal of Health Communication, 14(1), 15-42.

Prejean, J., Song, R., Hernandez, A., Ziebell, R., Green, T., Walker, F., \& HIV Incidence Surveillance Group. (2011). Estimated HIV incidence in the United States, 2006-2009. PLoS ONE, 6(8), e17502.

Rimal, R.N. (2000). Closing the knowledge-behavior gap in health promotion: The mediating role of self-efficacy. Health Communication, 12(3), 219-237.

Rothman, A.J. (2000). Toward a theory-based analysis of behavioral maintenance. Health Psychology, 19(1, Suppl), 64-69.

Rye, B.J., Fisher, W., \& Fisher, J. (2001). The theory of planned behavior and safer sex behaviors of gay men. AIDS and Behavior, 5(4), 307-317.

Savolainen, R. (2008). Everyday information practices: A social phenomenological perspective. Lanham, MD: Scarecrow Press.

Sheeran, P. (2002). Intention-behavior relations: A conceptual and empirical review. European Review of Social Psychology, 12(1), 1-36.

Sheeran, P., Abraham, C., \& Orbell, S. (1999). Psychosocial correlates of heterosexual condom use: A meta-analysis. Psychological Bulletin, 125(1), 90-132.

Sheeran, P., \& Taylor, S. (1999). Predicting intentions to use condoms: A meta-analysis and comparison of the theories of reasoned action and planned behavior. Journal of Applied Social Psychology, 29(8), 16241675.

Sligo, F.X., \& Jameson, A.M. (2000). The knowledge-behavior gap in use of health information. Journal of the American Society for Information Science, 51(9), 858-869.

U.S. Food and Drug Administration. (2012, July 3). FDA approves first overthe-counter home-use rapid HIV test. [Press release.] Retrieved from http://www.fda.gov/NewsEvents/Newsroom/PressAnnouncements/ ucm 310542.htm

Veinot, T.C. (2009). Interactive acquisition and sharing: Understanding the dynamics of HIV/AIDS information networks. Journal of the American Society for Information Science and Technology, 60(11), 2313-2332.

Veinot, T.C. (2010). "We have a lot of information to share with each other": Understanding the value of peer-based health information exchange. Information Research, 15(4), paper 452.

Veinot, T.C., Harris, R.M., Bella, L., Rootman, I., \& Krajnak, J. (2006). HIV/AIDS information exchange in rural communities: Preliminary findings from a three province study. Canadian Journal of Information and Library Science, 30(3/4), 271-290.

Veinot, T.C., Meadowbrooke, C.C., Loveluck, J., Hickok, A., \& Bauermeister, J.A. (2013). How "community" matters for how people interact with information: Mixed methods study of young men who have sex with other men. Journal of Medical Internet Research, 15(2), e33. Retrieved from http://www.jmir.org/2013/2/e33/

Williamson, K. (2005). Ecological theory of human information behaviour. In K.E. Fisher, S. Erdelez, \& E.F. McKechnie (Eds.), Theories of information behavior: A researcher's guide (pp. 128-132). Medford, NJ: Information Today.

Willyard, C. (2012). Recommendation of HIV test brings diagnostic dilemma home. Nature Medicine, 18(6), 841.

Workowski, K.A., \& Berman, S. (2010). Sexually transmitted diseases treatment guidelines, 2010. MMWR Recommendations and Reports, 59, $1-110$. 